\title{
Meaning interventions in schools: Strategies for supporting healthy development and wellbeing in the lives of youth
}

\author{
Jessica L. Morse · Maeve B. O’Donnell · Arissa R. Walberg · Bryan J. Dik
}

\begin{abstract}
Human beings inherently make meaning of the world, interpreting themselves in context and utilizing these representations to determine what to think, how to feel, and in what way to act. Developing meaning in life appears to be a highly nuanced, personal journey and yet, research suggests that those who experience their lives as meaningful enjoy multiple physical and psychological benefits and are protected from various health risks. Beyond establishing a firm sense that life is meaningful, studies suggest that people of all ages who can 'make meaning' of their experiences, especially difficult experiences, may be protected from developing some mental and physical health concerns. Childhood and adolescence may be pivotal periods for the development of this well-being resource, and school offers an especially promising context for fostering meaning. Yet, there have been few articles that have explored how meaning and meaning-making can be woven into the school day. The current article attempts to address this gap in the literature by defining meaning and meaning-making, discussing the relevance of meaning from a developmental framework, and offering suggestions for applications for teachers and providers during the school day.
\end{abstract}

Keywords: meaning in life, health, eudaimonic wellbeing, positive psychology

\section{Introduction}

Schools provide opportunities for students to acquire knowledge, develop effective thinking skills, problem-solve, and build relationships with peers, teachers, and mentors. Yet when parents are asked to consider what is most important for a child's future, they often provide answers beyond critical-thinking and analytical skills, knowledge, and relationships. They want their children's lives to be healthy, happy, and meaningful (Seligman et al., 2009). In this vein, positive psychology urges a "more open and appreciative perspective regarding human potential, motives, and capacities" (Sheldon \& King, 2001, p. 216). School may provide an ideal context for engaging students in activities that leverage their strengths to promote personal growth and well-being, yet few empirical studies or theoretical papers have provided specific recommendations about how this can be accomplished during the school day. This paper addresses this gap in the literature by describing the importance of meaning across 
development, highlighting school as an important context for meaning, and providing recommendations for actionable strategies for fostering meaning in school settings.

\section{Meaning in Life and Well-Being}

Meaning in life is considered to reflect an individual's subjective, global sense about the nature of her or his existence. People have a sense that life is meaningful when they experience purpose, significance, and coherence (Steger, Frazier, Oishi, Kaler, 2006; Steger \& Martela, 2016). Purpose refers to an overarching, personally relevant aim for one's life, significance is the sense that one's life matters, and coherence refers to one's understanding of what one's life means (Steger, 2009). Meaning is thus defined as the degree to which people make sense of how they fit in the world, perceive their life as having an overarching mission or goal, and feel as though their life, or contributions, matter (Steger, 2009). Scholars typically distinguish between search for meaning, defined as the extent to which people are looking for meaning, and presence of meaning, or the extent to which people's lives feel meaningful (Steger et al., 2006). Whereas presence of meaning is widely accepted as a key indicator of psychological health, search for meaning in the absence of experiencing meaning has been associated with increased risk for mental health concerns and impaired well-being (Steger et al., 2006). Meaning has often been considered a facet of well-being, and yet, teasing apart contributing factors to well-being can often prove difficult. One example is the relationship between meaning and happiness.

Although meaning and happiness are often paired as facets of well-being, there are conceptual differences between them. Whereas meaning has primarily been conceptualized from a eudaimonic perspective, happiness has largely been considered hedonic in nature (Ryan \& Deci, 2001). The hedonic tradition targets the pursuit of sensation and pleasure while eudaimonic perspectives focus on living consistently with the true self, with less emphasis on subjective well-being (Ryan \& Deci, 2001). Happiness has been defined in multiple ways-from a fleeting emotional state to feelings of accomplishment-and as a subjective judgment by which people assess their quality of life favorably (Veenhoven, 1991; Delle Fave, Brdar, Freire, Vella-Brodrick, \& Wissing, 2011). Positive emotions and life satisfaction have dominated the hedonic tradition (Diener et al., 1985; Diener, 2000; Pavot \& Diener, 2008). Seligman and colleagues suggest that happiness per se should not be the target of intervention due to its fleeting nature, but rather pleasure, engagement, and meaning are sustainable pathways to more frequent experiences of happiness (Seligman, 2004; Peterson \& Seligman, 2004). Indeed, engagement and meaning account for the majority of variance in predicting happiness (Peterson et al., 2005; Vella-Brodrick et al., 2009; Gander, Proyer, \& Ruch, 2016; but see Kashdan, Biswas-Diener \& King, 2008, and King, Hicks, Krull, \& Del-Gaiso, 2006, for an alternative perspective). Although happiness and meaning are related, focusing on meaning and meaning-related activities may provide benefit beyond exclusively targeting happiness, subjective well-being, or pleasantness.

Experiencing meaning in life is associated with several facets of psychological wellbeing and physical health. For example, meaning is linked to positive affect (Coffey, WrayLake, Mashek, \& Branand, 2014), self-acceptance (Steger, Kashdan, Sullivan, \& Lorentz, 2008), motivation (Bailey \& Phillips, 2016), and relatedness (Coffey et al., 2014). Meaning also predicts improved physical health and longevity (Roepke, Jayawickreme, \& Riffle, 2014), which is 
partially explained by engagement in health-promoting behaviors and avoidance of healthrisking behaviors (e.g., Brassai, Piko, \& Steger, 2011). Thus, people who experience their lives as meaningful tend also to report high levels of psychological well-being and physical health.

People who have a steady sense that life is meaningful may also cope more effectively with stressful life events. When individuals' global sense that life is meaningful is discrepant from their appraised meaning of a stressful situation, they tend to engage in meaning-making processes focused on resolving the discrepancy (Park, 2010). These processes are varied and nuanced, but they include cognitive and emotional processing of the event motivated by a desire to make sense of it. As a result of this meaning-making process, a person may feel like they have made sense of the situation: accepting it, growing from it, experiencing an identify shift, changing their beliefs about the world, and/or restoring their sense of meaning in life. As a hypothetical example, consider Jared, a 15 year-old high school sophomore who experiences the sudden death of his father in a car accident. Because Jared believed the world was stable and predictable, the meaning of this highly stressful event could be highly discrepant with his global meaning framework. According to Park's (2010) meaning-making model, Jared would engage in processes to understand and make meaning of the tragic loss. Jared may eventually accept his father's death, and even perceive it as an opportunity for growth ("This means that I have to step up and help care for my siblings"). Alternatively, he may change his global beliefs ("The world is harsh and cruel") in ways that negatively impact his well-being. This model provides a framework from which to understand diverse experiences in responding to unexpected events that require adjusting previous conceptions of who we are, what we believe, and how we go about our lives.

Research reveals that many people experience highly stressful events during childhood. In a large-scale survey that assessed adverse childhood experiences (ACEs), more than half of participants reported at least one stressful event, such as experiencing psychological, physical or sexual abuse, witnessing violence, or living with people at high-risk for causing instability in the home or harm (e.g., substance abusers, mentally ill or suicidal, or previously imprisoned; Felitti et al., 1998). As adults, people who reported ACEs had significantly higher incidence of disease and were at increased risk of engaging in health-risking behaviors (e.g., smoking). However, adults who reported strength in meaning-making were protected to a significant extent from the negative impact of ACEs on their health and well-being as adults (Banyard, Hamby, \& Grych, 2017). Although we cannot presume from this study that adults who are good at making meaning of difficult events were necessarily able to do so in childhood, it seems reasonable to conclude that the presence of meaning-making abilities in adulthood resulted from the development and fine-tuning of these capabilities throughout childhood and adolescence. Thus, providing opportunities for youth to engage in meaning-making and explore meaning in a supportive environment may buffer against the deleterious effects of stressful childhood experiences on adulthood health.

\section{Meaning in Childhood and Adolescence}

Whereas there is a vast body of research on meaning in adolescents and young adults, research on children's experiences of meaning in life is just beginning to grow with the recent development of tools to adequately measure meaning in this population. In the past, little 
research focused on assessing meaning in childhood due to the assumption that children lack the abstract thinking capacity and reflective mechanisms to support meaning processes (e.g., Piaget, 1952). However, evidence suggests that children as young as 8 years old can think abstractly (Davydov \& Kilpatrick, 1990) and that young children can understand and express aspects of meaning (e.g., beliefs about the world, the self, and how the self interacts in the world, i.e., "self-in-world"; Park \& Folkman, 1997). The "Why?" questions so heavily prevalent in childhood may reflect this curiosity about how the world works, who they are, and if what they do matters. Thus, the comprehension and mattering aspects of meaning are arguably especially important in childhood.

Qualitative research reveals that children can describe their experiences and sense of meaning (e.g., Kang, Kim, Song, \& Kim, 2013; Salter \& Stallard, 2004) and make meaning from negative experiences (Orvell, Kross, \& Gelman, 2018). Recently, researchers developed and validated a measure to assess the presence and sources of meaning in the lives of children (MIL-CQ; Shoshani \& Russo-Netzer, 2017). Using this scale, researchers have found children who report high levels of meaning also report high levels of life satisfaction and positive affectivity (Shoshani et al., 2017). Others have found that children's self-reported meaning is positively associated with their overall well-being (St. John, 2017). Furthermore, research on the effects of positive psychology interventions for preschool through middle-school suggest that children are aware of meaning and can increase their sense of meaning, as we review shortly. Thus, evidence is accumulating to suggest that meaning is a crucial component of children's well-being, and that meaning can be measured and fostered among children.

Far more evidence suggests that meaning is important in adolescence. Research with adolescents suggests meaning is associated with key positive psychological indicators such as subjective well-being (Burrow, O'Dell, \& Hill, 2010), life satisfaction (Bronk, Lapsey, Talib, \& Finch, 2009) and resiliency (Bernard, 1991; Masten \& Reed, 2002). The importance of meaning during adolescence is unsurprising given its relevance to development and identity formation (Schwartz, Côte, \& Arnett, 2005; Burrow \& O’Dell, 2010). Theorists such as Erikson (1968) described adolescence as a time of self-exploration and self-discovery, and substantial research demonstrates that establishing meaning is central to healthy identity development (e.g., Damon, Menon, \& Bronk, 2003; Burrow, O’Dell, \& Hill, 2010; Kiang \& Fulignu, 2010). Emmons (1999) suggested that meaning also influences adolescents' aspirations and life trajectories. That is, establishing meaning in life involves sensemaking and identifying an overarching purpose from which smaller goals are set in order to pursue that purpose.

Research is beginning to identify the specific pathways through which meaning in life may facilitate optimal youth development. Meaning in life involves understanding one's personal fit in the world, which aids in feeling connected to life in general and to specific life domains. For youth, the role of student ordinarily is central to their identity, yet without a coherent sense of global meaning, it may prove difficult to envision how their education links to a long-term sense of purpose and significance. Indeed, youth who do not identify their lives as meaningful are less motivated by academic achievement (Damon, 2009), whereas higher levels of purpose predict better academic performance (Martin Sanz, Rodrigo, Garcia, \& Pastrana, 2017). Adolescents who report higher levels of meaning also report greater intrinsic motivation and better academic performance (Bailey \& Phillips, 2016). Meaning in life also 
appears to play a significant role in feeling connected to school and various career-related outcomes. In a sample of $9^{\text {th }}$ graders in Hong Kong, presence of meaning positively predicted participants' feelings of connectedness to school, career curiosity, and career confidence (Yuen \& Yau, 2015). Thus, experiencing a sense of purpose or meaning may enhance engagement and performance in school and promote feelings of confidence and future efficacy, which likely reinforces positive identity development and optimal growth.

Although a sense of purpose may result in positive outcomes, it is relatively common for adolescents to lack a clear sense of direction. Bronk and colleagues (2009) described many youth as "drifting," defined as a lack of engagement in purposeful goals and low levels of intention. Conversely, youth who engage in higher levels of exploration (perhaps motivated by a stronger search for meaning) are more likely to report higher purpose commitment as they get older (Burrow, O'Dell, \& Hill 2010). In fact, in the sample of Chinese students described above, high levels of searching for meaning were also positively associated with career curiosity, confidence, and connectedness to school. Thus, a motivation to find meaning and a willingness or openness toward vocational and identity exploration can promote growth. It would not be surprising to find that meaning in life and exploration facilitate one another in a mutually causal loop for adolescents. Encouraging youth to engage in exploration in order to find meaning will likely help them form stronger identities and take a more active approach to their future goals (e.g., Lawford \& Ramey, 2015).

Beyond academic achievement and engagement, meaning in life is tied to healthier lifestyle choices as well as better psychological and physical health among adolescents. Adolescents who report high levels of meaning in life are less likely to use substances or engage in other risky behaviors (Aloise-Young, Hennigan, \& Leong, 2001; Brassai, Piko, \& Steger, 2010). Beyond behavioral choices, youth who report presence of meaning in life endorse better psychological health (French \& Joseph, 2009; Schochet, Dadds, Ham, \& Montague, 2006; Brouzos, Vassilopoulos, \& Boumpouli, 2016; Vela et al., 2015), whereas youth who report low levels of meaning also report poorer mental health and psychosocial adjustment (Shek, 1992). Similarly, adolescents who report high levels of purpose also endorse greater life satisfaction and emotional well-being (Burrow et al., 2010; Kiang \& Fuligni, 2010; King et al., 2006), hope (Feldman \& Snyder, 2005), and agency (Schwartz, Côte, \& Arnett, 2005). Meaning in life may also augment other psychological resources in reducing risk for psychopathology. For example, in a sample of Filipino high school students, presence of meaning mediated the effects of grit in reducing depression (Datu, King, \& Valdez, 2018). In sum, research suggests that meaning in life plays an important role in adolescents' current and future physical and emotional health.

Theoretical assertions and research results also support the role of meaning as a protective factor for adolescents who are struggling or facing difficult life circumstances. In other words, meaning in life may protect or buffer against the influence of known risk factors for later psychopathology. For example, Machell, Disabato, and Kashdan (2015) found that adolescents living in poverty were less likely to engage in antisocial behaviors if they reported having a sense of purpose. Research also supports the role of meaning in reducing risk for suicidal ideation and behavior. Meaning in life has been found to predict decreased suicidal ideation over an 8-week period of time (Kleiman \& Beaver, 2013), reduced severity of suicidal ideation (Tan, et al., 2017) and decreased lifetime odds of experiencing suicidal ideation and 
suicide attempts (Kleiman, Adams, Kashdan, \& Riskind, 2013). Likewise, meaning in life has been found to moderate the relationship between mental health status and suicidal ideation such that children and adolescents who report less meaning are more likely to experience suicidal ideation when they report poor mental health (Tan et al., 2017). Similarly, meaning in life has been found to play a moderating role between bully victimization and subsequent suicidal ideation among $6^{\text {th }}-12^{\text {th }}$ grade boys and to mediate the relationship between bully victimization and suicidal ideation among $6^{\text {th }}-12^{\text {th }}$ grade girls (Henry et al., 2013). In essence, meaning may be a protective factor for adolescent boys who are bullied, while decreases in meaning may explain the relationship between bullying and suicidal ideation for girls.

Finally, research also suggests that meaning in life may moderate the relationship between trauma history and psychological distress including symptoms of depression (Krause, 2007; Owens, Steger, Whitesell, \& Herrera, 2009) and PTSD (Craig et al., 2013; Owens et al., 2009). In a sample of adults with a history of trauma, participants with a strong sense of meaning in life reported lower levels of depression compared to those with a weak or average sense of meaning (Krause, 2007). Similarly, among samples of college students with a history of trauma, both well-being (Triplett, et al., 2012) and posttraumatic growth (Kashdan \& Kane, 2011) have been shown to correlate positively with meaning in life. Shortly after the September $11^{\text {th }}$ terrorist attacks in the United States, students with high levels of meaning in life reported posttraumatic growth, while those with low meaning in life experienced higher levels of posttraumatic distress (Steger, Frazier, \& Zacchanini, 2008). Although research has not yet examined the role of meaning for trauma victims during adolescence, it is plausible that the same patterns found among adults and college students would be present for an adolescent sample, pointing to the adaptive role of meaning in life in coping with substantial challenges.

To summarize, building and maintaining a sense of meaning in life offers substantial advantages for youth and adolescents across many life domains. This points to the need to introduce interventions and strategies that foster meaning.

\section{Positive Psychology in Schools}

School mental health systems are generally not equipped to sufficiently prevent and treat the plethora of mental health concerns experienced by students (Stephan, Sugai, Lever, \& Connors, 2015). Positive psychological interventions in schools, however, are easily delivered by teachers and other school professionals and may supplement treatment for those experiencing mental health concerns and serve as a preventative measure for those who are not. Research on positive youth development suggests that strength-based approaches that focus on developing competencies (e.g., resilience, social skills, emotional regulation, a positive sense of identity) yield significant benefits that extend beyond addressing problem behaviors (Catalano et al., 2004; Larson, 2000; Rashid, 2015). Positive psychology interventions for adults have been found to decrease depressive symptoms even without a direct focus on doing so (Seligman, Steen, Park, \& Peterson, 2005), suggesting that such interventions may be well-suited for building strengths among all students while also assisting those experiencing mental health concerns.

Recent research on "positive education" interventions has focused on the effects of programs that combine traditional academic skills with competencies that foster well-being (Seligman et al., 2009). The most studied positive education program to date is the Penn 
Resiliency Program (PRP), which targets cognitive-behavioral and social skills for older elementary and middle school students in a structured format. Evidence suggests that PRP participation is related to reduced hopelessness, fewer behavioral problems, and less anxiety among students (Seligman et al., 2009). Furthermore, a recent meta-analysis reported that the PRP appeared to reduce and prevent depressive symptoms (Brunwasser, Gillham \& Kim, 2009). Another curriculum, the Positive Psychology Programme, focuses on character strength development for $9^{\text {th }}$ grade students in the United States. Although depression and anxiety were not impacted, students who participated in this program reported increased enjoyment and engagement in school. Furthermore, teachers (who were blind to intervention assignments) reported that character strengths related to learning (e.g., creativity) increased among participating students (Seligman et al., 2009).

Another school-based positive psychology intervention, the Maytiv program (Shoshani \& Slone, 2017; Shoshani, Steinmetz, \& Kanat-Maymon, 2016), has been implemented in Israeli preschools and middle schools. The program focused on enhancing students' well-being, school engagement, and school achievement through eight components, including meaning (based on the PERMA framework; Seligman, 2011). The Maytiv program sought to enhance students' sense of meaning through content directed at developing character strengths, mindfulness, and focus (Shoshani et al., 2016). Results of longitudinal randomized control trials indicate that preschoolers who took part in the program demonstrated more positive learning behaviors and increases in well-being, and middle school children who partook reported more positive emotions, better peer relations, greater emotional and cognitive engagement, and higher grade point average scores than did students in control conditions (Shoshani, et al., 2016, 2017).

To summarize, research on positive education conducted to date suggests that such interventions can reduce depressive symptoms and may promulgate a more positive attitude toward school. Future research is needed to identify the "critical ingredients" of such interventions, addressing the question of which specific positive psychology constructs offer the most benefit for students. Future intervention work also needs to propose interventions that serve as an adjunct to already established routines in school, as it is not reasonable to expect that schools would want to or have the resources available to implement a positive psychology curriculum in addition to the regular curriculum.

Based on the review of literature in the present paper, it is proposed that meaning in life may be one of the key ingredients in promoting well-being for students and can be plausibly implemented in schools. Therefore, the subsequent sections focus on 1) current meaning interventions and 2) proposed meaning interventions that can be implemented by teachers and other school professionals.

\section{Meaning in Life Interventions}

To date, meaning intervention research has followed two primary paths. The first path can be described as studies that investigate meaning as a mediator for another primary outcome of interest. For example, one study found that meaning increased as a result of substance abuse treatment (Flora \& Stalikas, 2012), which supports meaning as a subsidiary outcome. The second path includes studies designed with the goal of enhancing meaning as the outcome of 
interest in its own right. For example, a study of college students who were assigned to take pictures of meaningful aspects of their lives experienced their lives as more meaningful as a result (Steger, Shim, Barenz, \& Shin, 2013). Recent efforts have used randomized control trial methodology as well, as in the case of meaning-centered group psychotherapy for cancer patients, which was found to significantly improve patients' sense of meaning relative to a control group (Breitbart et al., 2010). To summarize, available evidence suggests that meaning is indeed malleable and that focused interventions can enhance meaning. However, although purpose interventions have been piloted (e.g., Dik, Steger, Gibson \& Peisner, 2012), comprehensive meaning interventions remain untested in school-aged populations.

Steger and Martela (2016) defined meaning as the extent to which one understands oneself (i.e., comprehension), pursues goal-directed avenues in the world based on this understanding (i.e., purpose), and feels that one's existence is important (i.e., mattering). This definition lends itself well to interventions tailored to children and adolescents as activities can be designed to focus on developing each of the three components, recognizing also that interventions directed at purpose, for example, may also impact one's sense of mattering. To enhance comprehension of the self, activities that promote self-exploration, evaluation of strengths, exploration of values, and what things/people/ideas are meaningful to them may be beneficial. Fostering comprehension of the self may be especially beneficial for youth who experience low self-esteem, who over-identify with one aspect of their identity (e.g., "an athlete"), who do not have a well-developed sense of identity, or who are undergoing a critical transition or making a big decision (e.g., puberty, college decision making). To foster a sense of purpose, effective intervention strategies may encourage action, such as assigning students tasks that align with their purpose and interests, encouraging them to engage with the outside world in concrete ways. For example, a student with a heart for animal welfare may volunteer for the Humane Society or start a neighborhood pet-sitting service. Meaning also can be considered a reflexive process, such that feedback from engaging with their purpose(s) may help students to understand themselves better. Youth who might particularly benefit from interventions focused on developing purpose include those who feel unmotivated, lack efficacy, or experience depression and students who struggle in traditional school domains but thrive in creative, artistic, athletic, or other activities. Finally, to tap into mattering, interventions may focus on helping students identify times when they feel that they matter or are important, times when they feel connected to others through the work they do or interactions they have, or times when they feel what they are doing may make a positive impact on their communities. Mattering-focused interventions may be especially critical for youth who are depressed, feel socially isolated, experience bullying or teasing, receive minimal attention at home, or experience low self-esteem. Table 1 provides suggestions for schoolbased activities that teachers of children and adolescents can employ in the classroom to promote meaning. Previously researched and novel interventions are presented below:

Table 1. School-Based Meaning Activities

\begin{tabular}{llll}
\hline & Comprehension & Purpose & Mattering \\
\hline Childhood & $1,2,4,16$ & $6,7,8$ & 14 \\
\hline Adolescence & $3,4,5,16$ & $9,10,11$ & 12,13 \\
\hline
\end{tabular}


1. Point out strengths when a student is participating in activities, including how a student uses strengths to accomplish a task or to help another student. This may expand students' perceptions of their strengths, enhance self-understanding, and improve selfesteem and self-efficacy. For example: "Hannah, I noticed that you were frustrated at first with these math problems, but you were able to use your strength of perseverance to finish the task." (Park \& Peterson, 2008)

2. Point out student values by identifying how a student uses a value to make a choice or to help another student. This may expand students' understanding of what is important to them, encouraging thoughtful decision-making and perspective-taking and perhaps reducing impulsivity. For example: "Charlie, I saw that you were deciding between working with the Legos or spending time with Steve. You chose to play with Legos. It seems like it was important to you to be building in that moment." (Park \& Peterson, 2008)

3. Ask students to complete a strengths test whereby they respond to a series of questions related to their strengths. Ask them to come prepared with their reactions to the survey, including strengths that made sense for them and if they were surprised by anything as related to the survey. This may expand students' knowledge of their strengths, enhance self-understanding and reflective abilities, and improve self-esteem by allowing them to see themselves at their best. For a list of strengths, visit www.viacharacter.org (Peterson \& Seligman, 2004)

4. Ask students to take pictures of aspects of their life that they find meaningful. Ask students to choose 1-2 pictures that they would share with the class (Steger et al., 2013.). This activity may encourage planning, reflective skills, social connectedness, and a deeper understanding of what is important to them and why.

5. Ask students to choose a song that they find meaningful. Play a portion of the song in class and ask the student to elaborate on what makes this song meaningful to them. This activity allows for creativity and use of reflective skills and may promote social connectedness and a deeper understanding of what is important to them and why.

6. Take students on a field trip and encourage them to do something that fits with an area of strength. For example, if the class goes to a nursing home, encourage students to choose ways to be helpful based on skills or competencies they possess (Seligman, 2004). This activity may promote students' sense of purpose by providing opportunities for them to enact their strengths and act consistently with their values.

7. Encourage students to ask their parents/caregivers about times when they have exhibited their strengths. Encourage students to ask their parents/caregivers about other ways to use their strengths. Consider making this a homework assignment. This activity may expand students' understanding of themselves through feedback from others and may encourage flexibility in self-views as well as expansiveness in potential ways to express strengths.

8. Encourage students to ask their parents/caregivers about times when they have exhibited their values. Encourage students to ask their parents/caregivers about other ways to use their values. Consider making this a homework assignment. This activity may expand students' understanding of themselves through feedback from others and 
may encourage flexibility in self-views as well as expansiveness in potential ways to employ values.

9. Provide experiential homework, whereby students choose one strength and engage in an activity that demonstrates this strength. Ask students to come back to school prepared to share their experience. This activity encourages active engagement that may provide students with a sense of efficacy, enhance their sense of purpose, clarify who they are and what they care about, and potentially feel connected to others and motivated to continue engaging in activities that utilize strengths.

10. Provide experiential homework, whereby students choose one value and engage in an activity that demonstrates this value. Ask students to come back to school prepared to share their experience. This activity encourages active engagement that may provide students with a sense of efficacy, enhance their sense of purpose, clarify who they are and what they care about, and potentially feel connected to others and motivated to continue engaging in activities that align with their values.

11. Ask students to tell a story about a time when they used a strength/value. If this is difficult, begin by inviting students to identify strengths/values they admire in movie characters or books (Niemiec, \& Wedding, 2013). This activity provides youth with an opportunity to reflect on times when they or others are at their best. This may enhance self-esteem and self-efficacy and may encourage action in engaging with strengths and values.

12. Encourage students to keep a "Why I Matter" journal to document ways they made a difference in the lives of others. Encourage students to evaluate their responses and determine if there are themes in their responses. Research suggests that reflective journaling promotes self-examination, self-discovery, understanding of the self in the context of the world, critical thinking skills, as well as positive behavior changes and use of coping skills (e.g., Kelley, Cunningham, \& Branscome, 2015). Reflective writing on the topic of "Why I Matter" may specifically promote students' sense of meaning and understanding of what contributes to their sense of mattering.

13. Encourage students to keep a "Connectedness" journal. Each day students can write about a time when they felt most fully themselves and/or times when they most felt connected to other people or to their environment. Reflective writing on the topic of connectedness may promote students' sense of social well-being, self-and-other knowledge, and their overall sense of the ways in which connectedness promotes a sense of meaningfulness.

14. Encourage students to ask their parents/caregivers for feedback about ways they see their child making a difference in the world. Students can ask parents/caregivers to share stories about times the student did something that mattered or made a difference in the lives of others. This activity may expand students' understanding of themselves through feedback from others and may encourage flexibility in self-views and may provide an experience of feeling recognized and of value to others.

15. Ask students to write about the most difficult circumstance that occurred during the last week. Provide time to reflect on how they can make meaning from their experience (e.g., acceptance, change in identity, change in global meaning, etc.). Reflective writing 
about difficult experiences with a focus on how to make meaning of the experience may provide students opportunities to examine difficult experiences from a meaning-making lens that enables them to develop an understanding of how they typically make sense of difficult events, and perhaps develop alternative ways of making sense that promote growth and well-being.

16. Encourage students to write down "Three Good Things" that occurred each day and reflect. Research suggests that gratitude journaling (e.g., "Three Good Things") enhances students' sense of meaning and their engagement in the classroom (e.g., Flinchbaugh, Moore, Chang, \& May, 2012).

\section{Summary and Conclusion}

Despite our theoretical and empirical assertions that fostering meaning in schools would be beneficial for youth, it is likely that schools will experience barriers to implementation of positive psychology interventions (White, 2016). The stringent, standardized requirements of many public school systems in the United States may make it difficult for schools to acquire the approvals and resources necessary to train school personnel and effectively implement interventions. Although many positive psychology interventions do require extensive training and rigorous standardization, the activities contained in this article were designed to be brief and accessible and build on the foundational knowledge teachers possess in implementing and debriefing activities. Buy-in from teachers, parents, communities, and policy makers is critical in the efficacy of any intervention. Thus, psychoeducation about the nature, purpose, and benefits of integrating positive psychology interventions in the classroom is crucial in securing support. Ideally, a member of the school personnel would champion the efforts and serve as the primary resource for dissemination of knowledge and problem-solving as concerns arise (Sánchez et al., 2014). Although barriers to implementing meaning-focused interventions are inevitable, schools are environments with abounding intellectual, social, and structural resources with which to help youth understand what makes their lives meaningful.

Risks to youth and adolescent health are a concern that has garnered worldwide attention. Positive psychological interventions designed to promote human flourishing may be a critical piece in addressing youth health needs and to provide opportunities for students to flourish even in the midst of difficult life circumstances. Broadly speaking, positive psychological interventions in schools demonstrate compelling results, including reductions in depressive symptomatology and increases in academic strengths and engagement. As research attempts to identify those facets of well-being most important for intervention, meaning in life appears to impact several domains of children's and adolescent's health, including mental wellbeing and physical health, perhaps through the promotion of positive behavior and the reduction of health risk behavior. Meaning is also highly relevant to the school setting as youth tend to perform poorly and are at higher risk for dropping out of school when they do not perceive of school as meaningful. Easy-to-implement and accessible interventions in schools that help promote domain-specific meaning (e.g., school) and global meaning may serve as an antidote to the emotional and behavioral risks to which youth are particularly prone and promote optimal psychological and identity development. 


\section{Authors}

Jessica L. Morse

Colorado State University

jessica.morse@colostate.edu

Maeve B. O'Donnell

Colorado State University \& University of Washington

Arissa R. Walberg

Community Health of Central Washington

Bryan J. Dik

Colorado State University

\section{Publishing Timeline}

Received 14 May 2019

Accepted 23 September 2019

Published 26 September 2019

\section{References}

Aloise-Young, P. A., Hennigan, K. M., \& Leong, C. W. (2001). Possible selves and negative health behaviors during early adolescence. The Journal of Early Adolescence, 21(2), 158-181.

Bailey, T. H., \& Phillips, L. J. (2016). The influence of motivation and adaptation on students' subjective well-being, meaning in life and academic performance.Higher education research $\mathcal{E}$ development, 35(2), 201-216.

Banyard, V., Hamby, S., \& Grych, J. (2017). Health effects of adverse childhood events: Identifying promising protective factors at the intersection of mental and physical well-being. Child Abuse $\mathcal{E}$ Neglect, 65, 88-98.

Bernard, B. (1991). Fostering resiliency in kids: Protective factors in the family, school, and community. Retrieved from http://files.eric.ed.gov/fulltext/ED335781.pdf

Brassai, L., Piko, B. F., \& Steger, M. F. (2011). Meaning in life: Is it a protective factor for adolescents' psychological health?. International Journal of Behavioral Medicine, 18(1), 44-51.

Brunwasser, S. M., Gillham, J. E., \& Kim, E. S. (2009). A Meta-analytic review of the Penn Resiliency's Program's Effect on Depressive Symptoms. Journal of Consulting and Clinical Psychology, 77(6), 10421054.

Bronk, K., Hill, P. L., Lapsley, D. K., Talib, T. L., \& Finch, H. (2009). Purpose, hope, and life satisfaction in three age groups. The Journal of Positive Psychology, 4(6), 500-510.

Breitbart, W., Rosenfeld, B., Gibson, C., Pessin, H., Poppito, S., Nelson, C., ... \& Olden, M. (2010). Meaning-centered group psychotherapy for patients with advanced cancer: a pilotrandomized controlled trial. Psycho-Oncology, 19(1), 21-28.

Bryan, C. J., Elder, W. B., McNaughton-Cassill, M., Osman, A., Hernandez, A., \& Allison, S. (2013). Meaning in life, emotional distress, suicidal ideation, and life functioning in an active duty military sample. The Journal of Positive Psychology, 8(5), 444-452.

Burrow, A. L., O’Dell, A. C., \& Hill, P. L. (2010). Profiles of a developmental asset: Youth purpose as a context for hope and well-being. Journal of Youth and Adolescence, 39(11), 1265-1273. 
Catalano, R. F., Berglund, M. L., Ryan, J. A., Lonczak, H. S., \& Hawkins, J. D. (2004). Positive youth development in the United States: Research findings on evaluations of positive youth development programs. The annals of the American academy of political and social science, 591(1), 98-124.

Centers for Disease Control (2014). Youth Risk Behavior Surveillance-United States, 2013. Surveillance Summaries, 63(4), 2-168. Retrieved from http://www.cdc.gov/mmwr/pdf/ss/ss6304.pdf

Cheung, A. H., \& Dewa, C. S. (2006). Canadian Community Health Survey: Major Depressive Disorder and Suicidality in Adolescents. Healthcare Policy, 2(2), 76-89.

Coffey, J. K., Wray-Lake, L., Mashek, D., \& Branand, B. (2016). A multi-study examination of well-being theory in college and community samples. Journal of Happiness Studies, 17(1), 187-211.

Damon, W. (2009). The path to purpose: How young people find their calling in life. New York: Free Press Paperbacks.

Damon, W., Menon, J., \& Bronk, K. C. (2003). The development of purpose during adolescence. Applied Developmental Science, 7, 119-128.

Datu, J. A. D., King, R. B., \& Valdez, J. P. M. (2018). Psychological capital bolsters motivation, engagement, and achievement: Cross-sectional and longitudinal studies. The Journal of Positive Psychology, 13(3), 260-270.

Davydov, V. V. (1990). Types of Generalization in Instruction: Logical and Psychological Problems in the Structuring of School Curricula. Reston, VA: NCTM.

Dik, B. J., Steger, M. F., Gibson, A., \& Peisner, W. (2012). Make Your Work Matter: Development and pilot evaluation of a purpose-centered career education intervention. New Directions in Youth Development, 132, 59-73.

Emmons, R. A. (1999). The psychology of ultimate concerns: Motivation and spirituality in personality. New York: Guilford Publications.

Erikson, E.H. (1968). Identity: Youth and Crisis. New York: W. W. Norton \& Co.

Feldman, D. B., \& Snyder, C. R. (2005). Hope and the meaningful life: Theoretical and empirical associations between goal-directed thinking and life meaning. Journal of Social and Clinical Psychology, 24(3), 401-421.

Felitti, V. J., Anda, R. F., Nordenberg, D., Williamson, D. F., Spitz, A. M., Edwards, V., \& Marks, J. S. (1998). Relationship of childhood abuse and household dysfunction to many of the leading causes of death in adults: The Adverse Childhood Experiences (ACE) Study. American journal of preventive medicine, 14(4), 245-258.

Flora, K., \& Stalikas, A. (2012). Factors affecting substance abuse treatment in Greece and their course during therapy. Addictive behaviors, 37(12), 1358-1364.

Frankl, V. E. (1963). Man's search for meaning: an introduction to logotherapy. New York: Washington Square Press.

French, S., \& Joseph, S. (2009). Religiosity and its association with happiness, purpose in life, and selfactualization. Mental Health, Religion, \& Culture, 2, 117-120.

Henry, K. L., Lovegrove, P. J., Steger, M. F., Chen, P. Y., Cigularov, K. P., \& Tomazic, R. G. (2013). The potential role of meaning in life in the relationship between bullying victimization and suicidal ideation. Journal of Youth And Adolescence, doi:10.1007/s10964-013-9960-2.

Kang, K. A., Kim, S. J., Song, M. K., \& Kim, M. J. (2013). Effects of Logotherapy on Life Respect, Meaning of Life, and Depression of Older School-age Children. Journal of Korean Academy of Nursing, 43(1).

Kashdan, T. B., \& Kane, J. Q. (2011). Post-traumatic distress and the presence of post-traumatic growth and meaning in life: experiential avoidance as a moderator. Personality and Individual Differences, $50(1), 84-89$. 
Kiang, L., \& Fuligni, A. J. (2010). Meaning in life as a mediator of ethnic identity and adjustment among adolescents from Latin, Asian, and European American backgrounds. Journal of youth and adolescence, 39(11), 1253-1264.

King, L. A., \& Napa, C. K. (1998). What makes a life good? Journal of Personality and Social Psychology, 75, 156-165.

Kleiman, E. M., Adams, L. M., Kashdan, T. B., \& Riskind, J. H. (2013). Gratitude and grit indirectly reduce risk of suicidal ideations by enhancing meaning in life: Evidence for a mediated moderation model. Journal of Research in Personality, 47(5), 539-546.

Kleiman, E. M., \& Beaver, J. K. (2013). A meaningful life is worth living: Meaning in life as a suicide resiliency factor. Psychiatry Research, 210(3), 934-939.

Krause, N. (2007). Longitudinal study of social support and meaning in life. Psychology and aging, 22(3), 456-469.

Larson, R. W. (2000). Toward a psychology of positive youth development. American Psychologist, 55(1), 170-183.

Lawford, H. L., \& Ramey, H. L. (2015). “Now I know I can make a difference": Generativity and activity engagement as predictors of meaning making in adolescents and emerging adults. Developmental Psychology, 51(10), 1395.

Machell, K. A., Disabato, D. J., \& Kashdan, T. B. (2016). Buffering the negative impact of poverty on youth: The power of purpose in life. Social Indicators Research, 126(2), 845-861.

Martin Sanz, N., Rodrigo I.G., Garcia, C.I., \& Pastrana, P. A. (2017). Exploring Academic Performance: Looking beyond Numerical Grades. Universal Journal of Educational Research, 5(7), 1105-1112.

Masten, A. S., \& Reed, M. G. J.(2002). Resilience in development. Handbook of positive psychology, 74-88.

Niemiec, R. M., \& Wedding, D. (2013). Positive psychology at the movies: Using films to build virtues and character strengths. Hogrefe Publishing.

Oishi, S. \& Diener, E. (2013). Residents of poor nations have a greater sense of meaning in life than residents of wealthy nations. Psychological Science, 0956797613507286.

Orvell, A., Kross, E., \& Gelman, S. A. (2018). That's how "you" do it: Generic you expresses norms during early childhood. Journal of experimental child psychology, 165, 183-195.

Owens, G. P., Steger, M. F., Whitesell, A. A., \& Herrera, C. J. (2009). Posttraumatic stress disorder, guilt, depression, and meaning in life among military veterans. Journal of traumatic stress, 22(6), 654-657.

Park, C. L. (2010). Making sense of the meaning literature: An integrative review of meaning making and its effect on adjustment to stressful events. Psychological Bulletin, 136, 257-301.

Park, N., \& Peterson, C. (2008). Positive psychology and character strengths: Application to strengthsbased school counseling. Professional School Counseling, 12(2), 85-92.

Peterson, C., \& Seligman, M. E. (2004). Character strengths and virtues: A handbook and classification. New York: Oxford University Press and Washington, DC: American Psychological Association.

Piaget, J. (1952). The origins of intelligence in children (M. Cook, Trans.). New York: International Universities Press.

Rashid, T. (2015). Positive psychotherapy: A strengths-based approach. The Journal of Positive Psychology, 10(1), 25-40.

Roepke, A. M., Jayawickreme, E., \& Riffle, O. M. (2014). Meaning and health: A systematic review. Applied Research in Quality of Life, 9(4), 1055-1079.

Salter, E., \& Stallard, P. (2004). Posttraumatic growth in child survivors of a road traffic accident. Journal of Traumatic Stress: Official Publication of The International Society for Traumatic Stress Studies, 17(4), 335-340. 
Sánchez, V., Hale, R., Andrews, M., Cruz, Y., Bettencourt, V., Wexler, P., \& Halasan, C. (2014). School wellness policy implementation: insights and recommendations from two rural school districts. Health promotion practice, 15(3), 340-348.

Schwartz, S. J., Côté, J. E., \& Arnett, J. J. (2005). Identity and agency in emerging adulthood two developmental routes in the individualization process. Youth $\mathcal{E}$ Society, 37, 201-229.

Seligman, M. E. (2004). Authentic happiness: Using the new positive psychology to realize your potential for lasting fulfillment. Simon and Schuster.

Seligman, M. E., Ernst, R. M., Gillham, J., Reivich, K., \& Linkins, M. (2009). Positive education: Positive psychology and classroom interventions. Oxford Review of Education, 35(3), 293-311.

Seligman, M. E., Steen, T. A., Park, N., \& Peterson, C. (2005). Positive psychology progress: Empirical validation of interventions. American Psychologist, 60(5), 410-421.

Sheldon, K. M., \& King, L. (2001). Why positive psychology is necessary. American Psychologist, 56(3), 216217.

Shochet, I. M., Dadds, M. R., Ham, D., \& Montague, R. (2006). School connectedness is an underemphasized parameter in adolescent mental health: Results of a community prediction study. Journal of Clinical Child and Adolescent Psychology, 35(2), 170-179.

Shoshani, A., \& Russo-Netzer, P. (2017). Exploring and assessing meaning in life in elementary school children: development and validation of the meaning in life in children questionnaire (MILCQ). Personality and Individual Differences, 104, 460-465.

Shoshani, A., \& Slone, M. (2017). Positive Education for young children: Effects of a positive psychology intervention for preschool children on subjective well-being and learning behaviors. Frontiers in Psychology, 8, 1-11.

Shoshani, A., Steinmetz, S., \& Kanat-Maymon, Y. (2016). Effects of the Maytiv positive psychology school program on early adolescents' well-being, engagement, and achievement. Journal of School Psychology, 57, 73-92.

Steger, M. F. (2009). Meaning in life. In S.J. Lopez and C.R. Snyder (Eds.), The Oxford Handbook of Positive Psychology (2nd Edition), 1-11. New York: Oxford University Press.

Steger, M. F., Frazier, P., Oishi, S., \& Kaler, M. (2006). The Meaning in Life Questionnaire: Assessing the presence of and search for meaning in life. Journal of Counseling Psychology, 53, 80-93.

Steger, M. F., Frazier, P., \& Zacchanini, J. L. (2008). Terrorism in two cultures: Traumatization and existential protective factors following the September 11th attacks and the Madrid train bombings. Journal of Trauma and Loss, 13(6), 511-527.

Steger, M. F., Kashdan, T. B., Sullivan, B. A., \& Lorentz, D. (2008). Understanding the search for meaning in life: Personality, cognitive style, and the dynamic between seeking and experiencing meaning. Journal of Personality, 76(2), 199-228.

Steger, M. F., Oishi, S., \& Kashdan, T. B. (2009). Meaning in life across the life span: Levels and correlates of meaning in life from emerging adulthood to older adulthood. Journal Of Positive Psychology, 4, 43-52.

Steger, M. F., Shim, Y., Barenz, J., \& Shin, J. Y. (2014). Through the windows of the soul: A pilot study using photography to enhance meaning in life. Journal of Contextual Behavioral Science, 3(1), 27-30.

Steger, M. F., Shim, Y., Rush, B. R., Brueske, L. A., Shin, J. Y., \& Merriman, L. A. (2013). The mind's eye: A photographic method for understanding meaning in people's lives. The Journal of Positive Psychology, 8(6), 530-542.

Stephan, S.H., Sugai, G., Lever, N., \& Conners, E. (in press). Strategies for integrating mental health into schools via a multitiered system of support. Child and Adolescent Psychiatric Clinics. 
Triplett, K. N., Tedeschi, R. G., Cann, A., Calhoun, L. G., \& Reeve, C. L. (2012). Posttraumatic growth, meaning in life, and life satisfaction in response to trauma. Psychological Trauma: Theory, Research, Practice, and Policy, 4(4), 400-410.

White, M. A. (2016). Why won't it stick? Positive psychology and positive education. Psychology of wellbeing, 6(1), 2.

Yuen, M., \& Yau, J. (2015). Relation of career adaptability to meaning in life and connectedness among adolescents in Hong Kong. Journal of Vocational Behavior, 91, 147-156. 